\title{
Exploring Professionals' Experiences in the Rehabilitation of Older Clients with Dual-Sensory Impairment*
}

\author{
Sarah A. Fraser, ${ }^{1}$ Kenneth E. Southall, ${ }^{2}$ and Walter Wittich ${ }^{3}$ (1)
}

\begin{abstract}
RÉSUMÉ
En vue de mieux comprendre et d'améliorer le processus de réadaptation des personnes âgées présentant à la fois une déficience auditive et visuelle, soit une double déficience sensorielle (DDS), cette étude s'est penchée sur les perspectives des professionnels de la santé qui œuvrent chez cette population. Treize professionnels aux parcours variés ont été interviewés en lien avec leur expérience de travail auprès de personnes âgées avec DDS. Les entrevues ont été transcrites et codées, et une analyse de contenu a été effectuée. Les participants des diverses professions ont perçu qu'ils devaient assumer les rôles additionnels suivants : (1) conseiller, (2) guide, (3) formateur ou rééducateur. Ces rôles consistaient à aider les personnes avec DDS et leurs familles présentant une dépression, des problèmes d'acceptation, des consultations répétées et des parcours complexes dans le système de santé. Selon les professionnels interviewés, ces rôles supplémentaires accroissent leur charge de travail et les confrontent à des problématiques pour lesquelles ils n'ont pas reçu de formation. Ils suggèrent l'implantation d'une formation sur les DDS pour les professionnels et les membres de la famille concernés, ainsi qu'une approche de réadaptation en équipe multidisciplinaire.
\end{abstract}

\begin{abstract}
To better understand and improve the rehabilitation process of older adults with sensory losses in both hearing and vision or dual sensory impairment (DSI), this study explored the perspectives of health care professionals who work with this population. Thirteen individuals, with varied professional backgrounds, were interviewed about their experiences in working with older adults with DSI. We transcribed and coded the interviews, then conducted content analysis. Regardless of their professional backgrounds, the participants reported additional roles that they perceived they fulfilled: (a) counsellor, (b) navigator, and (c) trainer and re-trainer. These roles involved helping individuals with DSI, and their family, with depression, acceptance, repeat consultations, and way-finding through the health system. From the professionals' perspective, these additional roles increase workload and place them in situations they were not trained for. They suggest education for all professionals and for family members working with people with DSI; moreover, they suggest a multidisciplinary team rehabilitation approach.
\end{abstract}

1 Interdisciplinary School of Health Sciences, Faculty of Health Sciences, University of Ottawa

2 School of Social Work, McGill University, Montreal

3 School of Optometry, University of Montreal; CRIR/Centre de réadaptation MAB-Mackay du CIUSSS du Centre-Ouest-de-l'Île-de-Montréal; and CRIR/Institut Nazareth et Louis-Braille du CISSS de la Montérégie-Centre, Montréal

* This work was supported by a provincial grant from the Ministère de la famille et des ainés (Québec).

Manuscript received: / manuscrit reçu : 18/05/18

Manuscript accepted: / manuscrit accepté : 07/12/18

Mots-clés : vieillissement, double déficience sensorielle (DDS), réadaptation, professionnels de la santé, soins de santé

Keywords: aging, dual sensory impairment (DSI), rehabilitation, health care professionals, health care

Canadian Journal on Aging / La Revue canadienne du vieillissement 38 (4) : 481-492 (2019)

Copyright (C) Canadian Association on Gerontology 2019. This is an Open Access article, distributed under the terms of the Creative Commons Attribution licence (http://creativecommons.org/licenses/by/4.0/), which permits unrestricted re-use, distribution, and reproduction in any medium, provided the original work is properly cited. 
La correspondance et les demandes de tirés-à-part doivent être adressées à : / Correspondence and requests for offprints should be sent to:

Sarah A. Fraser, Ph.D.

Interdisciplinary School of Health Sciences

Faculty of Health Sciences

25 University Private

University of Ottawa

Ottawa, ON K1N 6N5

(sarah.fraser@uottawa.ca)

\section{Introduction}

The probability of co-morbidities increases with age (Marengoni et al., 2011). The presence of multiple chronic health conditions increases the complexity of care and has resulted in the development of guidelines that are intended to facilitate the organization of care provision, specifically for clinicians ("Guiding Principles for the Care of Older Adults", 2012). These guidelines and other reports suggest that many health professionals, including nurses and occupational therapists, have expressed that they do not have the training to communicate and effectively intervene with older adults who have combined hearing and vision losses (Campion, Awang, \& Ward, 2010; Deacy, Yuen, Barstow, Warren, \& Vogtle, 2012; Wittich, Barstow, Jarry, \& Thomas, 2015). An overview of dual sensory impairment suggests that interdisciplinary training of health care providers and strong support for communication is needed (Saunders \& Echt, 2007). However, to date, documentation of the perspectives of health care professionals who provide care for older adults with vision and hearing losses remains limited - a gap in knowledge this project aimed to fill.

Deafblindness has been defined as the presence of untreatable impairments of both vision and hearing, independent of order of onset (Dammeyer, 2014). However, in the context of age-related or acquired losses, the term dual sensory impairment (DSI) has been more commonly used (Wittich, Southall, Sikora, Watanabe, \& Gagne, 2013). The population prevalence of DSI is estimated to be around 0.74 to 5 per cent (Dawes et al., 2014; Kwon, Kim, Kim, Kwon, \& Yu, 2015; Swenor, Ramulu, Willis, Friedman, \& Lin, 2013), and dramatically increases up to 20-37 per cent when examining sub-populations of older adults (e.g., Cimarolli \& Jopp, 2014; Roets-Merken, Zuidema, Vernooij-Dassen, \& Kempen, 2014; Yamada et al., 2015). Among individuals who access rehabilitation services for DSI, between 69 and 85 per cent are over the age of 65 (Dammeyer, 2013; Wittich, Watanabe, \& Gagne, 2012). Taken together, these data suggest increasing numbers of older adults with DSI who are or will be seeking rehabilitation services in the coming years.
Much of the research on DSI rehabilitation has focused on understanding psychosocial outcomes (e.g., Brennan \& Bally, 2007; Heine, Erber, Osborn, \& Browning, 2002; Parfyonov, Mick, Pichora-Fuller, \& Wittich, 2016; Tiwana, Benbow, \& Kingston, 2016), the effect DSI has on spouses and relationship dynamics (Lehane et al., 2016), as well as screening for DSI and measuring functional outcomes (Guthrie et al., 2018; McGilton et al., 2016; Wittich, Höbler, Jarry, \& McGilton, 2018). Often, individuals with DSI have unmet needs or have sought treatment and rehabilitation services for one condition but not the other (Schneider et al., 2012). The lack of public awareness of the high incidence of DSI in older adults puts this population at risk for loss of independence (Brennan, Su, \& Horowitz, 2006), higher levels of depression, limitations in communications and social activities (Viljanen, Törmäkangas, Vestergaard, \& Andersen-Ranberg, 2014), and even mortality (Gopinath et al., 2013). Research on the rehabilitation process of people with DSI has begun to explore both gaps in service as well as strengths and challenges concerning the rehabilitation of this particular population (McMahon et al., 2017; Saunders \& Echt, 2011; Wittich, Jarry, Groulx, Southall, \& Gagné, 2016). Despite the increasing attention that research involving older individuals with DSI now receives, there is a need for additional work on the factors that influence the rehabilitation process and on the role of health care professionals working with this population.

Generally, the literature highlights the increased risk of negative consequences for people with DSI. Often, health care professionals provide advice and tools (e.g., assistive devices) for one impairment and do not consider the impact of having dual losses (Saunders \& Echt, 2007), resulting in compromised device usability (Wittich, Southall, \& Johnson, 2016). Although there seems to be enhanced risk of negative consequences, there is also evidence that many people with DSI have residual hearing and/or vision and that targeted rehabilitation could improve their social participation and functional outcomes (Wittich et al., 2012). The research that documents health care professionals' perspectives on the rehabilitation of DSI is sparse, but recent 
qualitative research interviewing professionals to gain more insight into issues surrounding multimorbidity has provided important insights into the care of older adults with two or more complex conditions (Luijks et al., 2012; McNamara et al., 2017; Vermunt et al., 2018).

In the case of older adults with DSI, one study has explored nurses' roles and perceptions of a selfmanagement rehabilitation strategy for older adults in long-term care with DSI (Roets-Merken et al., 2016). In their longitudinal qualitative study, Roets-Merken et al. (2016) found that nurses initially held negative perceptions about the benefits of a self-management program for individuals with DSI. Yet, after working with these individuals, the nurses had a more positive perspective on the benefits of the program, and they also gained insights concerning adaptations needed in their approach to better support this clientele. In order to foster self-management of DSI, nurses were urged to "go beyond protocol thinking" (pg. 1).

Altogether, there is a growing number of older adults with DSI who have unmet needs or who have only been treated for impairment in one sense (Schneider et al., 2012). Further, research on negative psychosocial outcomes in DSI suggests that, in order to adapt to and ameliorate outcomes, we need a better understanding of the rehabilitation process. To build an enhanced understanding of older individuals with DSI, and to improve their rehabilitation process, it is necessary to document the perspectives of those most intimately involved in this process. Beyond reporting the perceptions of individuals with DSI (LeJeune, 2010), it is important to understand the perspectives of the health care professionals who work with this population. In the current study, we expected that health professionals working with older individuals with DSI would be able to identify important issues in the rehabilitation process when describing their role in it. The aim of this study was to describe and better understand the experiences of health care professionals in the rehabilitation of older individuals with DSI in order to inform rehabilitation practices for this population.

\section{Methods}

We adopted a qualitative description approach (Sandelowski, 2000). The objective of this approach is to present in-depth summaries of participant experiences in everyday language without complex interpretation. This approach is often used to investigate health care delivery to answer questions such as Who uses a service? and What facilitates or is a barrier to service use? (Butler \& Fox, 2018; Mousing, Timm, Lomborg, \& Kirkevold, 2018; Sandelowski, 2000). The protocol was approved by the Centre de recherche interdisciplinaire en réadaptation institutional ethics review board (CRIR \# 855-0713), in accordance with the Declaration of Helsinki, and all participants provided informed written consent.

To be included in the study, the health care professionals we solicited had to have worked with older individuals with DSI. We selected a purposeful sampling strategy (Suri, 2011) in order to document the health care professionals' views on core - as well as variable - aspects of professional experience with older adults who had DSI. Of the 14 health care professionals we approached and who fit the inclusion criteria, 13 consented to participate in this study. One participant agreed to participate but was not interviewed due to scheduling conflicts. Nine of the participants were recruited from private practice or centres for low vision/DSI programs in Montreal, Toronto, and Halifax (Canada). The remaining four participants were recruited at the Envision Conference 2013 held in Minneapolis, Minnesota (United States). Participants from this conference included two professionals from Waterloo, Canada, and two from the U.S. states of Alabama and Kansas. With the exception of a general practitioner (\#13; see Table 1) who stated "my practice is heavily skewed towards older people" and reported that he saw older individuals with DSI in his practice, all of the participants were affiliated with a low-vision rehabilitation centre and saw clients with DSI. More than half of the professionals worked in a DSI program $(n=8)$. The age of participants ranged from 28 to 66 years. Participant characteristics are described in Table 1. All participants received \$30 CAN for their time.

All one-on-one interviews were conducted by the first author (SF) at the participant's workplace or at the conference site. The interview guide included open-ended questions about day-to-day practice and experiences working with older adults with DSI (see the supplementary Interview Guide, Appendix A). This interview guide was developed by the first and second authors (SF, KS) and then tested with a health care professional who works in a DSI program. After the interview, the professional provided feedback on the interview guide, and the guide was adapted accordingly. We used this professional's interview to improve subsequent interviews with professionals but did not include it in the current sample. In the guide, participants were asked about positive and negative experiences when serving older adults with DSI (e.g., What are your main care priorities for clients with hearing and vision impairment?). To better understand participant perspectives concerning their role in the rehabilitation process, we posed questions about facilitators and barriers (e.g., What is the typical course of treatment for 
Table 1: Participant characteristics

\begin{tabular}{|c|c|c|c|c|}
\hline Participants & Specialty & Sex & Years Practicing & DSI Years \\
\hline 1 & Occupational therapist, CLVT & Female & 12 & 9 \\
\hline 2 & Occupational therapist, PhD, CLVT & Female & 28 & 17 \\
\hline 4 & Optometrist, BSc & Female & 14 & (14) \\
\hline 5 & Audiologist & Female & 2 & 2 \\
\hline 6 & CLVT & Female & $<1$ & $<1$ \\
\hline 9 & Case manager: DSI program & Female & 22 & 16 \\
\hline 10 & Intervener: Project lead & Female & $>11.5$ & 11.5 \\
\hline 11 & Orientation and mobility specialist & Female & $\approx 20$ & 11 \\
\hline 12 & Independent living specialist ${ }^{b}$ & Female & 18 & 4 \\
\hline 13 & General practitioner ${ }^{c}$ & Male & 27 & $(27)$ \\
\hline
\end{tabular}

Note. CLVT = Certified low vision therapist; $\mathrm{DSI}=$ dual sensory impairment; $\mathrm{PhD}=$ Doctor of philosophy; $\mathrm{BSc}=\mathrm{Bachelor}$ of sciences; a Intervener = professional who becomes the eyes and the ears for the individual with DSI in order to facilitate communication; b Independent living specialist = professional who helps people to improve their ability to perform tasks of daily living and working environment for optimal functioning; ${ }^{c}$ General practitioner $=$ Medical doctor educated and trained in family medicine; DSI years = number of years working with people with DSI; those with (brackets) around the number of years are participants who did not specify years specific to DSI.

someone with DSI?). The duration of the audiorecorded interviews ranged from 40 to 90 minutes.

Verbatim transcriptions were prepared, anonymized, and each assigned a numerical identifier. We analysed the transcripts using content analysis, which is appropriate when there is limited knowledge about a research topic (Hsieh \& Shannon, 2005). Content analysis has three steps: open coding, creating categories, and abstraction (Elo \& Kyngäs, 2008). We read each transcript repeatedly as we searched for text that answered our research question: What are the perceived role(s) of health care professionals in the rehabilitation of older individuals with DSI? Text that answered this question was highlighted and assigned a label, a technique known as open coding (Huberman \& Miles, 1994). The objective of this task is to ensure that all text that addressed the basic question be assigned a code. Once all the transcripts had been coded a first time (by first author SF), the code list represented a preliminary coding schema. On multiple occasions during data analysis, the first author met with the co-authors to discuss the codes and possible themes arising from them. Discrepancies in codes were discussed primarily between the first and second author and resolved after deliberation to the satisfaction of the both authors. Discrepancies often involved providing a better description of what the code represented in order to avoid miscoding. On occasion, this involved the merging of smaller codes that were representative of the same idea.

Next, we examined the coding schema for overlapping or connected opinions and experiences. When intersecting codes were identified, and it made sense to combine the codes, we created categories of codes (Patton, 2002). During this phase of the analysis, we prepared memos that detailed patterns within the data deemed fundamental to answering the research question (Morse \& Field, 1995). The category is characterized as "saturated" when the core ideas of a category remain stable despite ongoing data collection (Szabo \& Strang, 1997). At this point, data collection typically ceases. In this study, we found that the code categories were saturated after 10 interviews. As a group, we decided to conduct three more interviews to ensure that our code categories were stable (i.e., we were not uncovering new information to be added to categories). Our coding of these additional interviews confirmed that we had indeed reached saturation of categories for the research question.

The memos documented repeating intersections of codes across interviews. We synthesized memos and discussed them in team meetings. We undertook the final step of content analysis - abstraction - after we had prepared general descriptors of the analysis (Polit \& Beck, 2004). In this step, we selected representative interview excerpts for inclusion in this article. The first and second authors (SF, KS) discussed any discrepancies in coding and/or themes until agreement was reached.

\section{Results}

Our analyses uncovered that, in addition to their traditional discipline-specific roles (i.e., optometrist, audiologist, etc.) in working with older adults who have DSI, the professionals reported they additionally take on the roles of (a) counsellor, (b) navigator, and (c) trainer 
and re-trainer. Quotations from the study participants will include their professional occupation and participant number from Table 1.

\section{Counsellor}

Study participants expressed the fact that clients often arrived in their office not understanding the changes that were occurring in their bodies nor the accompanying emotions. Nor did they have a sense of how to move forward towards recovery. This situation resulted in the professional's taking on the role as confidante and trusted adviser: ergo, counsellor. The counsellor role was embodied by the health care professionals' building a rapport with their client that became a gateway for discussions about emotions related to the client's vision and hearing loss. Additionally, the counsellor's role encompassed dealing with clients' expectations of living with multiple impairments, the progression of the impairments, and the benefits of rehabilitation along with client readiness for counselling and changing health status.

In the counsellor role, the health care professional provided professional support to the clients upon hearing their diagnosis and during rehabilitation. This often involved managing emotions and sometimes helping the client with family members who did not understand the implications of the diagnosis and were not always supportive of the client or the rehabilitation proposed. Professionals who encountered the individuals with DSI first were those who conducted initial screening assessments (i.e., optometrist, audiologist, general practitioner), and as one of the first contacts, they reported being solicited by the individual for help with coming to terms with the DSI diagnosis. Even professionals who saw clients after the initial assessment and were assisting in activities of daily living or mobility spoke of the rapport they built that often involved helping their clients cope with a series of emotions. For example, an independent living specialist (\#12) with 18 years of experience (4 years specific to DSI) talked about encouraging a couple to seek counselling because the client's lack of spousal support was affecting the client's rehabilitation process:

We did counselling because his wife was kind of a pushy gym teacher type and she couldn't understand why he wouldn't just get up and go, but sometimes in the earlier days when he would just get up and go he would just fall right over because he didn't have the balance, and there were some other stuff going on so he would just pass out. So she would get frustrated; he was frustrated. He was often, during our sessions, sending her away.

As none of our participants were social workers, many expressed discomfort with this role and the inadequate training to manage psychosocial aspects of DSI: "We didn't have a counsellor for a while ... I was overwhelmed with all of the emotion; I am not a counsellor, but trying to provide them with the best [information], and make the referrals ... I was going crazy!" (Optometrist, \#3).

The stress of the counsellor role was also echoed in the comments of an intervener (a professional who becomes the eyes and the ears for the individual with DSI in order to facilitate communication) (\#8):

There tends to be a range of mental health issues with a lot of clients that we encounter but we're really not trained for that ... a lot of these individvals are challenged with just depression and just acceptation of "I'm deafblind now".

The professionals also reported that clients could be in various stages of acceptance of their condition and that this might affect their willingness to seek further help. The independent living specialist (\#12) in our sample described such an experience with a client:
In the beginning when they are first diagnosed they're not always ready to think about it or in an emotional place to accept the help. They need a kind of cooling off period, I think. Some people are like, "OK, this has happened, I've got to move on." Other people are like "Don't even come near me. I'm not- I don't even want to think about that right now."

Another participant (manager for DSI, \#9) described counselling clients to manage family members. The family members seemingly discouraged their parents' independence and certain rehabilitation strategies because they wanted to keep their parents safe:

Sometimes the family can be, hum, they're a great support but they can almost be a deterrent to the parents going further. Because "Oh no, mom, no, no, no, mom will never go outside no, no, no! She can't see any more!" But she can see but not the way she used to, right? And they're very protective but it holds the parents back.

\section{Navigator}

Most of the codes in this role involved barriers during the referral process and the difficulty for the older adult with DSI to access or be referred to specific programs and services needed for their complex health condition. Several professionals mentioned older adults reporting difficulty navigating the medical system and asking for guidance:

We basically tell people: If your vision is impeding in your daily life in any way then you should come see us. [We] even find some ophthalmologists who are hesitant. (Why?) Misinformation. "Oh you don't need that yet, you're not bad enough". (Independent living specialist, \#12) 
In clinics that did not have multidisciplinary teams or that lacked certain specialties (i.e., social worker, audiologist), study participants spoke about the fragmented state of the system and difficulty tracking down help that addressed the needs of their clients. One intervener (\#10) expressed disappointment with other medical professionals who are not receptive to the needs of this clientele and lack the patience to communicate the needed medical information:

\begin{abstract}
In a medical setting the amount of time it takes for communication or especially with a senior and the communication piece with a senior, they [medical doctors] get frustrated really quickly and they'll turn their back and say "just tell her this", walk out of the room and "tell her I said this", you know and [l say] "excuse me ... you'll have to come back and tell her yourself, please", you know?
\end{abstract}

Many participants devised workarounds to account for limited resources. Examples of this included participants building makeshift assistive devices for the older adult that would accommodate both losses and aid overall functioning. Other participants described finding financing for clients who required rehabilitation (e.g., providing assistive devices from a loan program).

\begin{abstract}
I think a big issue, especially in this province in particular, is income, and budget and finances; this province does not have coverage for assistive devices ... we have items that have been donated back to us from previous clients ... and we can then give it to people who need it! ... I hate to see people come in and I hate to sense that it's a financial issue - I hate that. So if I have something, I'll give it to them. (Certified low vision therapist, \#6)
\end{abstract}

In addition, eligibility criteria for vision and hearing services and device access were often reported as barriers to utilizing available rehabilitation services. Often, it was a health care professional who is working in one domain (i.e., low vision) who realized that their client may also have hearing loss. As this is not the professional's area of expertise, they can raise the concern with their client and provide a resource and/or guide the individual to the proper service. Despite this, some clients will not be receptive, thereby creating a barrier towards the professional's being a successful navigator. One participant described training an individual with low vision to cross the street. After starting the training, the participant realized that the client had a unilateral hearing loss:

There're some clients - they're in denial about the hearing loss ... So many times you come up to the intersection and you know that they need to listen to the surge [or traffic] and one client in particular, he doesn't get on the left ... But on the left he says to me, "No, no l've been to the doctor, they're fine, they're fine" ... So, people are in denial. (Orientation and mobility specialist, \#1 1 1)

Some professionals expressed that offering multiple services can be too much for their clients:

The community care access centre ... and so what they want is to increase referrals within the different [programs/services]. So we are working on that, so Meals-on-Wheels, day programs, you know, getting more cross-referrals. And it's a learning process; I also think that you can't do everything all at once, it's overwhelming. And I think you [the client] lose some of your confidence in yourself if you say "Okay, you need Meals on Wheels, you need housekeeping, you need shopping, you need ... okay, well let's take it step-wise," otherwise it's all what you can't do as opposed to what you can do. (Optometrist, \#3)

\section{Trainer and Re-trainer}

This role encompasses treatment or rehabilitation options for chronic and progressive conditions that require multiple ongoing interventions over time. Treatment and rehabilitation options included providing available devices for function and maintenance of independence and a reluctance of clients to rely or impose on people - friends and family - close to the person with DSI. An important component of this role was that the professionals reported seeing the clients repeatedly as their health conditions changed/ progressed. These changes brought about new challenges and needs that invoked additional intervention and, often, education of family and other professionals about the client's changing abilities. As such, the professionals who were trainers for challenges and needs at an early stage of change in vision and/or hearing also frequently re-evaluated and provided supplemental rehabilitation to the same individuals (re-trainer role). One professional stated: "So now, she's called me back because I think her vision has diminished even more and she does have hearing loss as well, so it would be probably re-teaching her because she had enough vision before that." (Orientation and mobility specialist, \#11)

In close relation to the findings in the counsellor role, an occupational therapist (\#2) also spoke about multiple interactions with the same client as that client came to accept rehabilitation services for DSI:

I think that they're probably at a better level of acceptance with their disability themselves ... maybe they were dealing with something new and they weren't ready to accept that they need to do things differently and accept new equipment and 
new techniques, but after some adaptation and probably frustration with not being able to do some things, they come back.

In this role of training/retraining, families can be a catalyst or a hindrance to successful treatment outcomes across repeated visits with the health care professionals as the clients' conditions worsen and safety becomes a concern. The orientation and mobility specialist (\#11) found that her role encompassed educating the family during these transitions:

Safety is usually what it is. It's safety and just not ... knowing what's out there. So, it's our job to educate them: "I'm going to show you how your mom can do this and she'll be safe, she'll be fine." And then maybe allowing their parent to take the ownership of their own safety.

This same professional also expressed how education was necessary with other health care professionals in order to address safety issues:

I've worked with clients in nursing homes [where] the staff doesn't want them to get up out of their bed and use their cane and, you know, go around. Because I guess it's the liability ... we've done services at places like this and we've explained to them the cane, what it does and the purpose of it. And it's been successful where we have been able to educate the staff enough that the person gets to keep their independence.

Another professional (independent living specialist, \#12) remarked that change in severity or capacity may also require an adjustment and retraining using new and potentially unexpected technologies:

Others talk about introducing technology as a possible approach to some of their vision (or hearing) loss. Some people are [open to technology]. Some people will tell me "Oh, I'm too old for that." Then I show them, I have a tablet that I bring with me, that's my own ... I change the size and the contrast and say, "So what do you think of this?" [They respond] "Wow I could read that! ...Wow I could do that!"

\section{Discussion}

The goal of this study was to describe and better understand the experiences of health care professionals in the rehabilitation of older individuals with DSI. Findings emerging from the analyses suggest that health care professionals perceive several roles beyond the specific role they were trained for (i.e., optometrist, audiologist, etc.), including counsellor, navigator, and trainer and re-trainer. The results suggest an increased load on professionals working with older individuals with DSI and systemic and social issues that could influence the rehabilitation process of these clients.

\section{Importance of Counselling for DSI}

One of the most frequently mentioned roles by the participants in our sample was that of the counsellor. Interestingly, despite the diverse backgrounds of the professionals, most felt that they were being asked to fill a counsellor role. This role embodied being solicited for or managing clients' emotional and mental health issues. The professionals described these issues as related to the clients' acceptance or rejection of their change in vision and/or hearing and creating understanding about the condition with other family members. In line with the psychosocial work on individuals with DSI (Brennan \& Bally, 2007; Saunders \& Echt, 2007), it is not surprising that professionals might be solicited for counselling support as there are many psychosocial issues associated with this condition (Heine \& Browning, 2014). In addition, as evidenced in the trainer and re-trainer role, many of these professionals see these clients repeatedly as clients' vision or hearing changes, or work directly with the clients on a day-to-day basis (i.e., intervener) and in so doing develop rapport. This repeated contact might facilitate the client's "opening up" to the professional. From the perspective of the health care provider, taking on the counsellor role was an added stressor. This was not a role for which they had extensive or appropriate training, and many were uncomfortable when solicited to fulfill this role.

Despite many of these professionals having recourse to a professional trained in psychosocial issues (via referral or someone on their team), they mention that clients, particularly older individuals, may not be open to accepting treatment from a mental health professional (Conner et al., 2010; Corrigan, 2004; Sirey et al., 2001). Age-based stigma against mental health treatment can influence help-seeking for psychosocial components of DSI and may ultimately influence acceptance of rehabilitation options and slow the rehabilitation process (Fraser, Kenyon, Lagacé, Wittich, \& Southall, 2016). In line with the literature on psychosocial issues and DSI, some professionals mentioned that time may be a factor in the acceptance of the condition and readiness for rehabilitation (Brennan \& Bally, 2007). Certain health care professionals talked about their counselling role, not only for the client but their family members, who did not accept the change in their loved one's condition or who were actively trying to keep the older adult safe. This family-centred care is reflected in current priorities of the rehabilitation profession (Singh et al., 2017; Wahl, 2013). Beyond this type of professional support during the rehabilitation process, education about DSI can help to reduce the psychosocial impact associated with the condition and to educate others about the capabilities and accommodations 
that may be necessary for an individual with DSI to maintain independence (Livneh, Chan, \& Kaya, 2014).

\section{Wayfinding through the Health System}

Another role that the professionals in this sample felt they fulfilled was as a navigator through the health care system. Literature that compares the adult and child care systems demonstrates that once an individual reaches adulthood, care is rarely located in a central location; the individual often has to seek out or ask for appropriate services or referrals, and in most cases the individual is expected to single-handedly consolidate and make sense of all the medical/rehabilitation information that is provided (Sharma, O'Hare, Antonelli, \& Sawicki, 2014; Stange, 2009).

Some of the professionals in our study sought to help the individuals with DSI to manoeuver through the system and maximize access to health services from multiple sources. Certain professionals talked about the complex needs of clients with DSI and noted that older clients in particular often had to manage many health conditions with very different care plans. This finding aligns well with research on multimorbidity in aging ("Guiding Principles for the Care of Older Adults", 2012), which argues for a very careful approach by health care professionals that centres care plans on the clients' needs and allows the client to decide which of their many health care needs should be addressed and which may not be a priority for them at this time. As one of the participants in our sample mentioned, it can also be overwhelming to the older adult to be presented with multiple services or care plans, which can focus the individual on the impairments in their health rather than on the capacities they still maintain.

Health professionals discussed others' (i.e., general practitioners') lack of awareness of the rehabilitation services available and resistance to send a client to these services because their condition was not severe enough, a finding that has previously been observed in sensory rehabilitation (Overbury \& Wittich, 2011). Even among hearing and vision professionals, Dullard and Saunders (2016) found that sensory losses are rarely taken into account when selecting a rehabilitation intervention. Further, interactions within the health system could at times be strained as communication with the individual about their health is paramount, but this communication often occurs in a context in which the physician has little time even as older individuals with DSI need more time for communication. In the quote presented earlier in the Navigator section, the professional did not even speak directly to the individual with DSI, but rather communicated with their intervener in order to speed up the process. There are clear health consequences to the individual if health information is not being communicated adequately, and this underscores the importance of improving awareness about DSI to all health professionals that are developing multidisciplinary teams to address complex health conditions (Heine \& Browning, 2002; Saunders \& Echt, 2007).

Several professionals discussed the challenges of locating and acquiring rehabilitation solutions, often with respect to assistive devices, because their clients could not afford the devices or services offered. A number of the professionals in the sample mentioned that there are programs that subsidize devices for people who have served in the military. For those older adults who were not veterans and financially could not afford the service or device provided, some of the professionals found workarounds in which they loaned a device for trial or re-used returned devices in order to assist their client. ${ }^{1}$ Financial restrictions that hinder the acquisition of assistive devices could lead to further loss of functioning and social participation and ultimately an increase in health care needs and costs.

\section{Trainer and Re-Trainer Role Revisited}

In a rehabilitation setting, it is perhaps not surprising that many feel that they become trainer and re-trainers as a client's vision and hearing changes and perhaps other age-related changes in health develop. Some health professionals spoke of these repeated visits as very important in the rehabilitation process during which several clients needed time to accept these sensory changes in order to accept the rehabilitation services provided. Much like the professionals who do not refer because the condition is not "bad enough", many clients may perceive that their condition does not warrant rehabilitation and so may refuse rehabilitation services when they are first offered (Saunders \& Echt, 2007). In combination with professionals' developing a rapport (counsellor role) at the retraining stage with clients (on subsequent visits), older clients might be more open to the services provided, and this will facilitate the aims of the health care professional to achieve the goals of the client in their care plan.

A key component of this role of trainer and re-trainer involves educating the client, their family members, and other health care professionals about the changes in the client's health condition along with implications of these changes and possible rehabilitation options. Although informing the client about options is certainly an expected component of a health professional's job, many participants indicated that retraining extended to family members or staff assisting the older adult. 
In the retraining process, the professionals often found that family members and staff (i.e., at a nursing home) reverted to keeping the older adult safe which ultimately restricted the older adult's independence and level of participation. The professionals felt the need to educate family members and staff on what the older adult could still accomplish safely on their own. Competence in performing activities of everyday living can be called into question in people with DSI (Tiwana et al., 2016) and other combined complex conditions (i.e., dementia and low vision).

Complex interactions of this sort may require family and professionals to weigh the benefits of safety versus independence (Lawrence \& Murray, 2010). Although the literature on this topic is sparse, Roets-Merken et al. (2016) suggested that health care professionals do allow negative perceptions of self-management programs for people with DSI to influence their decisionmaking. One of the key components for changing this according to Roets-Merken et al. is facilitating communication between the professionals and older adults with DSI. The professionals in our study sample supported this proposition and, cutting across all the roles discussed, they reported that education, training, and working with people with DSI can change perceptions and ultimately improve rehabilitative outcomes for this clientele.

\section{Limitations}

It is important to note that, despite seeking a varied sample of health professionals (in age, training, and years of service), this group of professionals may have different training and previous experiences compared with professionals who do not have regular contact with individuals with DSI. With the exception of one professional, the majority of participants in this study sample worked regularly with older adults with DSI or were a part of a DSI program. This meant that they were aware of the complexities that the condition poses and, in most cases, actively sought solutions to improve their clients' independence and quality of life. The outcomes of these interviews might have been different if we had recruited health care professionals who rarely consult with clients who have DSI. In addition, although different professionals were solicited and all worked with individuals with DSI, we had only one audiologist in our sample and several (four) professionals who were specialists in vision, which may limit the generalizability of the perspectives reported.

\section{Conclusion}

These findings suggest that DSI is a complex condition that has repercussions on the roles performed by health care professionals who work with this population.
Professionals who work with this population might be solicited to perform roles outside of their specific training. These additional roles can increase their workload, and can lead to performing new and unfamiliar tasks. There is a clear need for counselling services for this population, as well as education concerning this intersection of chronic conditions. It is also evident that a fragmented health system may contribute to the need for these additional roles. A majority of the sample suggested that a client-centred approach with a multidisciplinary team would best serve the needs of older individuals with DSI while maximizing their independence when possible.

\section{Supplementary Material}

To view supplementary material for this article, please visit https:/ / doi.org/10.1017/S0714980819000035

\section{Note}

1 Within Canada, eligible individuals in Quebec receive devices at no cost; in Ontario, the device is fully or partially covered depending on the device program and its eligibility requirements; in Halifax, only veterans have the cost of the device fully covered.

\section{References}

Brennan, M., \& Bally, S. J. (2007). Psychosocial adaptations to dual sensory loss in middle and late adulthood. Trends in Amplification, 11(4), 281-300. http://doi. org/10.1177/1084713807308210

Brennan, M., Su, Y. Y. P., \& Horowitz, A. (2006). Longitudinal associations between dual sensory impairment and everyday competence among older adults. Journal of Rehabilitation Research and Development, 43(6), 777-792.

Butler, J. I., \& Fox, M. T. (2018). Nurses' perspectives on interprofessional communication in the prevention of functional decline in hospitalized older people. Health Communication, 1-7. http:/ /doi.org/10.1080/10410236.2 018.1455141

Campion, C., Awang, D., \& Ward, G. (2010). Broadening the vision: The education and training needs of occupational therapists working with people with sight loss. British Journal of Occupational Therapy, 73(9), 413-421. http:// doi.org/10.4276/030802210X12839367526093

Cimarolli, V. R., \& Jopp, D. S. (2014). Sensory impairments and their associations with functional disability in a sample of the oldest-old. Quality of Life Research: An International Journal of Quality of Life Aspects of Treatment, Care and Rehabilitation, 23(7), 1977-1984. http://doi. org/10.1007/s11136-014-0657-0

Conner, K. O., Copeland, V. C., Grote, N. K., Koeske, G., Rosen, D., Reynolds, C. F., \& Brown, C. (2010). Mental health treatment seeking among older adults with depression: The impact of stigma and race. The American Journal 
of Geriatric Psychiatry: Official Journal of the American Association for Geriatric Psychiatry, 18(6), 531-543. http:/ / doi.org/10.1097/JGP.0b013e3181cc0366

Corrigan, P. (2004). How stigma interferes with mental health care. American Psychologist, 59(7), 614-625. http://doi. org/10.1037/0003-066X.59.7.614

Dammeyer, J. (2013). Characteristics of a Danish population of adults with acquired deafblindness receiving rehabilitation services. British Journal of Visual Impairment, 31(3), 189-197. http:/ / doi.org/10.1177/0264619613490518

Dammeyer, J. (2014). Deafblindness: A review of the literature. Scandinavian Journal of Public Health, 42(7), 554-562. http://doi.org/10.1177/1403494814544399

Dawes, P., Dickinson, C., Emsley, R., Bishop, P. N., Cruickshanks, K. J., Edmondson-Jones, M., ... Munro, K. (2014). Vision impairment and dual sensory problems in middle age. Ophthalmic \& Physiological Optics: The Journal of the British College of Ophthalmic Opticians (Optometrists), 34(4), 479-488. http://doi.org/10.1111/ opo.12138

Deacy, R. M., Yuen, H. K., Barstow, E. A., Warren, M., \& Vogtle, L. K. (2012). Survey of the low vision rehabilitation curricula in occupational therapy and occupational therapy assistant programs. The American Journal of Occupational Therapy: Official Publication of the American Occupational Therapy Association, 66(6), e114-e118. http://doi.org/10.5014/ajot.2012.005124

Dullard, B., \& Saunders, G. H. (2016). Documentation of dual sensory impairment in electronic medical records. Gerontologist, 56(2), 313-317. http://doi.org/10.1093/ geront/gnu032

Elo, S., \& Kyngäs, H. (2008). The qualitative content analysis process. Journal of Advanced Nursing, 62(1), 107-115. http://doi.org/10.1111/j.1365-2648.2007.04569.x

Fraser, S., Kenyon, V., Lagacé, M., Wittich, W., \& Southall, K. E. (2016). Stereotypes associated with age-related conditions and assistive device use in Canadian media. The Gerontologist, 56(6), 1023-1032. http://doi.org/ 10.1093 /geront/gnv094

Gopinath, B., Schneider, J. M., McMahon, C. M., Burlutsky, G., Leeder, S. R., \& Mitchell, P. (2013). Dual sensory impairment in older adults increases the risk of mortality: A population-based study. PloS One, 8(3), e55054. http:/ / doi.org/10.1371/journal.pone.0055054

Guiding principles for the care of older adults with multimorbidity: An approach for clinicians. (2012). Journal of the American Geriatrics Society, 60(10), E1-E25. http:// doi.org/10.1111/j.1532-5415.2012.04188.x

Guthrie, D. M., Davidson, J. G. S., Williams, N., Campos, J., Hunter, K., Mick, P., ... Wittich, W. (2018). Combined impairments in vision, hearing and cognition are associated with greater levels of functional and communication difficulties than cognitive impairment alone: Analysis of interRAI data for home care and long-term care recipients in Ontario. PLoS One, 13(2), e0192971. http://doi.org/10.1371/journal.pone.0192971

Heine, C., \& Browning, C. (2014). Mental health and dual sensory loss in older adults: A systematic review. Frontiers in Aging Neuroscience, 6(May), 83. http://doi. org/10.3389/fnagi.2014.00083

Heine, C., \& Browning, C. J. (2002). Communication and psychosocial consequences of sensory loss in older adults: Overview and rehabilitation directions. Disability $\mathcal{E}$ Rehabilitation, 24(15), 763-773.

Heine, C., Erber, N. P., Osborn, R., \& Browning, C. J. (2002). Communication perceptions of older adults with sensory loss and their communication partners: Implications for intervention. Disability and Rehabilitation, 24(7), 356-363. http:/ / doi.org/10.1080/09638280110096250

Hsieh, H. F., \& Shannon, S. E. (2005). Three approaches to qualitative content analysis. Qualitative Health Research, 15(9), 1277-1288.

Huberman, A. M., \& Miles, M. (1994). Data management and analysis methods. In N. K. Denzin \& Y. S. Lincoln (Eds.), Handbook of Qualitative Research (pp. 428-444). Thousand Oaks, CA: Sage.

Kwon, H., Kim, J., Kim, Y., Kwon, S., \& Yu, J. (2015). Sensory impairment and health-related quality of life. Iranian Journal of Public Health, 44(6), 772-782.

Lawrence, V., \& Murray, J. (2010). Balancing independence and safety: The challenge of supporting older people with dementia and sight loss. Age and Ageing, 39(4), 476-480. http:/ / doi.org/10.1093/ageing/afq054

Lehane, C. M., Elsass, P., Hovaldt, H. B., Dammeyer, J., (2016). A relationship-focused investigation of spousal psychological adjustment to dual-sensory loss. Aging $\mathcal{E}$ Mental Health, 22(3), 397-404.http: / / doi.org/10.1080/ 13607863.2016.1268091

LeJeune, B. J. (2010). Aging with dual sensory loss: Thoughts from consumer focus groups. AER Journal: Research and Practice in Visual Impairment and Blindness, 3(4), 146-152.

Livneh, H., Chan, F., \& Kaya, C. (2014). Stigma related to physical and sensory disabilities. In P. W. Corrigan (Ed.), The Stigma of Disease and Disability: Understanding Causes and Overcoming Injustices (pp. 93-120). Washington, D.C.: American Psychological Association.

Luijks, H. D., Loeffen, M. J., Lagro-Janssen, A. L., van Weel, C., Lucassen, P. L., \& Schermer, T. R. (2012). GPs' considerations in multimorbidity management: A qualitative study. British Journal of General Practice, 62(600), e503-e510. http:/ / doi.org/10.3399/bjgp12X652373

Marengoni, A., Angleman, S., Melis, R., Mangialasche, F., Karp, A., Garmen, A., ... Fratiglioni, L. (2011). Aging with multimorbidity: A systematic review of the literature. Ageing Research Reviews, 10(4), 430-439. http:/ / doi. org/10.1016/j.arr.2011.03.003 
McNamara, K. P., Breken, B. D., Alzubaidi, H. T., Bell, J. S., Dunbar, J. A., Walker, C., \& Hernan, A. (2017). Health professional perspectives on the management of multimorbidity and polypharmacy for older patients in Australia. Age and Ageing, 46(2), 291-299. http://doi. org/10.1093/ageing/afw200

McGilton, K., Höbler, F., Campos, J., Dupuis, K., Labreche, T., Guthrie, D., ... Wittich, W. (2016). Hearing and vision screening tools for long-term care residents with dementia: Protocol for a scoping review. BMJ Open, 6(7), e011945. http://doi.org/10.1136/bmjopen-2016011945

McMahon, C. M., Schneider, J. M., Dunsmore, M., Gopinath, B., Kifley, A., Mitchell, P., ... Leeder, S. R. (2017). Screening, education, and rehabilitation services for hearing loss provided to clients with low vision: Measured and perceived value among participants of the vision-hearing project. Ear and Hearing, 38(1), 57-64. http:/ / doi.org/10.1097/AUD.0000000000000351

Morse, J., \& Field, P. A. (1995). Qualitative research methods for health professionals (2nd ed.). Thousand Oaks, CA: Sage.

Mousing, C. A., Timm, H., Lomborg, K., \& Kirkevold, M. (2018). Barriers to palliative care in people with chronic obstructive pulmonary disease in home care: A qualitative study of the perspective of professional caregivers. Journal of Clinical Nursing, 27(3-4), 650-660. http:/ / doi. org/10.1111/jocn.13973

Overbury, O., \& Wittich, W. (2011). Barriers to low vision rehabilitation: The Montreal Barriers Study. Investigative Ophthalmology E Visual Science Science, 52(12), 8933-8938. http:/ / doi.org/10.1167/iovs.11-8116

Parfyonov, M., Mick, P., Pichora-Fuller, M., \& Wittich, W. (2016). Association between sensory loss and social outcomes: A preliminary report. Canadian Acoustics, 44(3), 124-125.

Patton, M. Q. (2002). Qualitative research E evaluation methods (3rd ed.). Thousand Oaks, CA: Sage.

Polit, D. F., \& Beck, C. T. (2004). Nursing research: Principles and methods. Philadelphia, PA: Lippincott Williams \& Wilkins.

Roets-Merken, L. M., Vernooij-Dassen, M. J. F. J., Zuidema, S. U., Dees, M. K., Hermsen, P. G. J. M., Kempen, G. I. J. M., \& Graff, M. J. L. (2016). Evaluation of nurses' changing perceptions when trained to implement a self-management programme for dual sensory impaired older adults in long-term care: A qualitative study. BMJ Open, 6(11), e013122. http:/ / doi.org/10.1136/bmjopen-2016-013122

Roets-Merken, L. M., Zuidema, S. U., Vernooij-Dassen, M. J. F. J., \& Kempen, G. I. J. M. (2014). Screening for hearing, visual and dual sensory impairment in older adults using behavioural cues: A validation study. International Journal of Nursing Studies, 51(11), 1434-40. http://doi. org/10.1016/j.ijnurstu.2014.02.006
Sandelowski, M. (2000). Focus on research methods: Whatever happened to qualitative description? Research in Nursing $\mathcal{E}$ Health, 23(4), 334-340. http://doi.org/ 10.1002/1098-240X(200008)23:4<334::AID-NUR9> 3.0.CO;2-G

Saunders, G., \& Echt, K. V. (2007). An overview of dual sensory impairment in older adults: Perspectives for rehabilitation. Trends in Amplification, 11(4), 243-258. doi: $10.1177 / 1084713807308365$

Saunders, G., \& Echt, K. V. (2011). Dual sensory impairment in an aging population. ASHA Leader, 16(3), 5-7.

Schneider, J. M., Gopinath, B., McMahon, C., Teber, E., Leeder, S. S. R., Wang, J. J. J., \& Mitchell, P. (2012). Prevalence and 5-year incidence of dual sensory impairment in an older Australian population. Annals of Epidemiology, 22(4), 295-301. http://doi.org/10.1016/j.annepidem. 2012.02.004

Sharma, N., O'Hare, K., Antonelli, R. C., \& Sawicki, G. S. (2014). Transition care: Future directions in education, health policy, and outcomes research. Academic Pediatrics, 14(2), 120-127. http://doi.org/10.1016/ j.acap.2013.11.007

Singh, G., Barr, C., Montano, J., English, K., Russo, F., \& Launer, S. (2017). Family-centered audiology care: Emotion and reason in hearing healthcare. Hearing Review, 24(5), 30-32.

Sirey, J. A., Bruce, M. L., Alexopoulos, G. S., Perlick, D. A., Raue, P., Friedman, S. J., \& Meyers, B. S. (2001). Perceived stigma as a predictor of treatment discontinuation in young and older outpatients with depression. The American Journal of Psychiatry, 158(3), 479-481. http:/ / doi.org/10.1176/appi.ajp.158.3.479

Stange, K. C. (Ed.) (2009). The problem of fragmentation and the need for integrative solutions. Annals of Family Medicine, 7(2), 100-103. http:/ / doi.org/10.1370/afm.971

Suri, H. (2011). Purposeful sampling in qualitative research synthesis. Qualitative Research Journal, 11(2), 63-75. http:/ / doi.org/10.3316/QRJ1102063

Swenor, B. K., Ramulu, P. Y., Willis, J. R., Friedman, D., \& Lin, F. R. (2013). The prevalence of concurrent hearing and vision impairment in the United States. JAMA Internal Medicine, 173(4), 1-5. http: / / doi.org/10.1001/ jamainternmed.2013.1880

Szabo, V., \& Strang, V. R. (1997). Secondary analysis of qualitative data. Advances in Nursing Science, 20(2), 66-74.

Tiwana, R., Benbow, S. M., \& Kingston, P. (2016). Late life acquired dual-sensory impairment: A systematic review of its impact on everyday competence. British Journal of Visual Impairment, 34(3), 203-213. http://doi. org/10.1177/0264619616648727

Vermunt, N. P., Harmsen, M., Elwyn, G., Westert, G. P., Burgers, J. S., Olde Rikkert, M. G., \& Faber, M. J. (2018). A three-goal model for patients with multimorbidity: 
A qualitative approach. Health Expectations: An International Journal of Public Participation in Health Care and Health Policy, 21(2), 528-538. http://doi.org/10.1111/ hex.12647

Viljanen, A., Törmäkangas, T., Vestergaard, S., \& AndersenRanberg, K. (2014). Dual sensory loss and social participation in older Europeans. European Journal of Ageing, 11(2), 155-167. http:/ / doi.org/10.1007/s10433-013-0291-7

Wahl, H. W. (2013). The psychological challenge of late-life vision impairment: Concepts, findings, and practical implications. Journal of Ophthalmology, 2013, Article ID 278135, 1-11. http:/ / doi.org/10.1155/2013/278135

Wittich, W., Barstow, E. A. A., Jarry, J., \& Thomas, A. (2015). Screening for sensory impairment in older adults: Training and practice of occupational therapists in Quebec. Canadian Journal of Occupational Therapy, 82(5), 283-293. http:/ / doi.org/10.1177/0008417415573076

Wittich, W., Höbler, F., Jarry, J., \& McGilton, K. (2018). Recommendations for successful sensory screening in older adults with dementia in long-term care: A qualitative environmental scan of Canadian specialists. BMJ Open, 8(1), e019451. http://doi.org/10.1136/bmjopen2017-019451

Wittich, W., Jarry, J., Groulx, G., Southall, K., \& Gagné, J.-P. (2016). Rehabilitation and research priorities in deafblindness for the next decade. Journal of Visual Impairment $\mathcal{E}$ Blindness, 110(July-August), 219-231.

Wittich, W., Southall, K., \& Johnson, A. (2016). Usability of assistive listening devices by older adults with low vision. Disability $\mathcal{E}$ Rehabilitation: Assistive Technology, 11(7), 564-571. http://doi.org/10.3109/17483107.201 5.1042076

Wittich, W., Southall, K., Sikora, L., Watanabe, D. H., \& Gagne, J.-P. (2013). What's in a name: Dual sensory impairment or deafblindness? British Journal of Visual Impairment, 31(3), 198-207. http://doi.org/10.1177/ 0264619613490519

Wittich, W., Watanabe, D. H., \& Gagne, J. P. (2012). Sensory and demographic characteristics of deafblindness rehabilitation clients in Montreal, Canada. Ophthalmic $\mathcal{E}$ Physiological Optics: The Journal of the British College of Ophthalmic Opticians (Optometrists), 32(3), 242-251. http://doi.org/10.1111/j.1475-1313.2012.00897.x

Yamada, Y., Denkinger, M. D., Onder, G., Finne-Soveri, H., van der Roest, H., Vlachova, M., ... Topinkova, E. (2015). Impact of dual sensory impairment on onset of behavioral symptoms in European nursing homes: Results from the Services and Health for Elderly in Long-Term Care study. Journal of the American Medical Directors Association, 16(4), 329-333. http://doi.org/10.1016/ j.jamda.2014.11.006 